\title{
THE GROWING THREAT: HOMELAND SECURITY ISSUES OF BULGARIA
}

\author{
Valeri RATCHEV
}

\begin{abstract}
This article presents the main problems in adapting security establishments of democratic countries to the challenges of spreading terrorism in a globalized world. The focus is on problems facing post-communist countries. The author argues that, both during the early stages of democratization and in the ongoing security sector reform, the emphasis is on democratic civilian control and too little attention is paid to operational effectiveness. Furthermore, all democratic countries face the problem of achieving effectiveness of the security organizations while preserving and protecting democratic values. The concept of homeland security, among others, may be used to strengthen international and interagency cooperation in dealing with the security challenges of the Twenty First century.
\end{abstract}

Keywords: Homeland Security, Human Security, Societal Security, Terrorism, Security Sector Reform.

Among the huge and still growing number of key issues discussed by the security experts in the aftermath of September 11 is the extent to which transnational terrorism has become 1) number 1 security threat, 2) threat to the liberal democratic world as a whole and not only to the US, and 3) how long will this threat remain dominant in the international and national security context. Let us all bear in mind the deeply emotional headline 'We are all Americans,' which appeared in one of the French newspapers on the day after the tragic events of September 11; two years later it was followed by 'We are all Spaniards,' which, however, left a touch of bitterness not so much due to the withdrawal of Spain from the coalition in Iraq but because of the inability of democrats to address their people in a democratic manner (i.e. directly and frankly). These were followed by the somber 'We are all Londoners' during the twominute silence on July 15, when thousands of people throughout Europe paid tribute to the victims of the latest terrorist attacks. It was amidst these emotional responses that we initiated the war against terror, replacing with spread of democracy as a way of curtailing terrorism (no longer 'killing the mosquitoes with a newspaper,' but 'draining the swamp they breed in'), as President Bush emphasized in his second in- 
auguration address. We have also completed the operation in Afghanistan with the total support of the entire international community and, in terms of rebuilding the nation, ended up with results which highly exceeded our expectations. We took part in the US-led campaign against Saddam Hussein, the outcome of which will become clear not within the next months or even years, but after decades.

Practically, the terrorist attacks in London mark a new chapter in this drama of the century. First, leading experts on transnational terrorism reached the conclusion that the search of its origin in the swamp of poverty, quicksand of religious fundamentalism or the clash between the 'rich North' and 'poor South' civilizations does not provide an answer to the question where should be the center of gravity in the war against terrorism. The London terrorist attacks show another aspect of the suicide bombers' image - altogether adjusted foreigners, never being subjected to any form of assimilation, brought up in well-to-do families with small business of their own, privileged to use all benefits of the free liberal democratic society and, alas, well acquainted with its flaws and vulnerabilities. According to British intelligence officials, their terrorist mentality takes the shape of blackmail against social and religious discrimination whose victims they think they are. If this assessment is correct, besides the religious motivation there is obviously a strong political factor wrapped in the haze of social injustice (we should keep in mind that Bin Laden himself is a multimillionaire, or at least was one in the wake of terrorism). Moreover, the MI5 experts are probably right when claiming that they are familiar not only with modern means of communication but also with the methods for conducting police investigation, the various obstacles in the relations among the institutions, media coverage and social compassion for suspects until their guilt is proven. There is one main issue which provokes and focuses our attention in regard to terrorism being the foremost threat in Europe (also). In relation to the London attacks, the Italian newspaper La Stampa ran an article about a demonstration against Israeli policy in Torino back in 2002, during which groups of Moroccan schoolchildren, educated in Italian schools, marched along dressed as suicide bombers.

Second, all current data, processes and trends confirm that terror will be the main threat to national and international security in the years to come: starting with the recruitment of suicide bombers, selecting the targets and ending with the ease with which all necessary items can be obtained; from oil prices to armament costs and the easy access to nuclear and missile know-how; from the continuous lack of effectiveness of the international organizations, vulnerability of interim coalitions to the lack of any short-term perspective for adjusting international law to real-life issues.

Third, it is quite obvious that the conceptualization of security in the $21^{\text {st }}$ century is bouncing back and forth in a triangle formed by democratic freedoms, transnational asymmetric threats, and efficient security systems. 
The highly ambitious US project called 'Homeland Security' turned out to be difficult for implementation by the Americans themselves, almost unfeasible for Western Europe and completely incomprehensible in Eastern Europe. Scandinavian research endeavors on contemporary crisis management systems are closer to the traditional East European models. They, however, cover a limited range of today's threats and do not involve active measures for countering terrorism and other threats beyond the country's national borders. The third principal notion nowadays is the concept of societal security. The reason to include this concept in the system of ideas and procedures was that the traditional concept of state security could not measure up to the inconsistent situation when, in some cases, strengthening of the security of state can turn into a threat to the society. This is typical not only for East European countries, but also for all other societies in which the security environment provokes an expectation for a strong hand, for order and discipline, for threats caused by minorities, etc.

This concept requires a phenomenal consolidation of society together with a strict control over the security sector in order to maintain a steady balance of their relationship in regard to effectiveness - democracy criterion.

Meanwhile, even the concept of the so-called 'Security Sector Reform' seems to be more like an idea for transforming security organizations from totalitarianism to democracy than an approach towards their modernization and optimization. Highlighting the aspect of democracy in the organization and functioning of the security forces - although a must from a political point of view - did little to enhance their efficiency in countering terrorism from an operational point of view. The reforms of the Armed Forces in different parts of the Euroatlantic space, which until recently were implemented in the range from revolution in military affairs to downsizing and modernization, turned out to be inappropriate and were replaced by the concept of transformation. In spite of the great efforts of the NATO's Allied Command Transformation, this concept is facing the extremely difficult task of reaching all member states of the Alliance as well as its potential non-allied partners around the globe. Even the idea for including 'small' states within the framework of developing niche capabilities cannot possibly make up for the lack of clear vision and could not fill in the technological gap and doctrinal deficiencies. Explanations for this vary from lack of mutual threat perception to lack of resources and limited national ambitions. As a result, too many questions arise and various issues, such as the role of the armed forces under the new circumstances and in the strategic future, their integrity as a whole (in terms of national defense and coalition operations) and the need of specific capabilities (necessary for countering terrorism), force planning (capabilities-based, threatbased or mission-based), and politically feasible framework of military acquisition, still remain unresolved. Expectations from the military are on the rise, no matter what they have proven, assumed or demonstrated so far. 
On the whole, the surfacing high degree of vulnerability of modern liberal societies along with the obviously inadequate resources of the existing homeland security organizations to cope with the newly emerged risks and threats are becoming a problem which we are not ready to face either from a notional, political or operational point of view. It is possible that the tragic events in London will make the free world more tolerant to police control on free movement (surveillance cameras on main crossroads, in subways), on communications (Internet and cellular), on bank accounts and transactions (for suspects charged with financially aiding terrorists). This will no doubt help the politicians and experts to provide a plausible answer to the question of what liberties we are prepared to sacrifice in order to ensure even an imperfect security. Practically, however, the key political issue concerning homeland security lies in finding the formulae in which achievements of democracy instead of being sacrificed are implemented in countering terrorism.

\section{Conceptual Level: Effective Security Policy Calls for Restricting the Scope of the Notion of 'Security'}

In its 1994 Annual Global Human Development Report, UNDP introduced a new concept of security. The ambitious goal was to transform it into a basic conceptual instrument. Due to its comprehensive and fundamental nature, the notion for the socalled 'human security' will have coordinating functions in many aspects of public life and serve as a basis for a great number of UNDP programs. The major issue in this case is that human security should not be set against national security. Initially we, especially the East European states for which homeland security was a matter of 'fatherland' and 'motherland' security during the Cold War, got the false impression that this is an entirely new level of security. We accepted it as a key element of the political transition and started to restructure many aspects of state security (border control, judiciary, address registration and monitoring, top secrecy on security, intelligence and counterintelligence issues on political presumption, etc.) without having any idea how to enhance human and societal security. With a background involving shock therapy, political and economic catharsis, lack of democratic responsibility and vague strategic environment, this was a very risky undertaking. We are still under the false impression that the traditional type of national security involves higher budget spending for security and defense compared with spending on human and societal security requirements. As the UNDP Report puts it, human security is multidimensional, the key aspects being economic security, food security, health security, environmental security, personal security, community security and political security. However, there is nothing original in this idea. Back in 1987, the UN General Assembly international conference on Disarmament and Development came up with a definition which reflects the new complex approach to security in the changing environment: “... Security is a top priority issue for all nations. It serves as a basis for 
both disarmament and social development. Security has not only military but also political, economic, social, humanitarian and environmental aspects."

Basically, the term security has always referred precisely to human security. As Stefan Popov, a Bulgarian analyst, once said, the problem is that “... throughout the Cold War human security was regarded and included in terms such as nation, sovereignty, territory, population. This is by no means substitution of one type of security with another. Providing security to the citizens involves a policy at the level of territorial defense, preparing for a massive attack, etc." Transnational terrorism has changed thoroughly this context, thus shifting the focal point from security of the state attributes (sovereignty, territorial integrity and independence, as guaranteed by the Constitution of Bulgaria) to security of critical infrastructure, information networks, political process, ethnic relations, social balance in all its aspects - economical, psychological, etc. The scope of the term security can be spread on indefinitely. As a result, the initial term security becomes even more vague and wide-ranging. It turns out that the very effort to make human security the target of policy actions has been rendered useless with the introduction of this term. Taking a broad approach to security might become a risky precedent for the management process if the basic concept is not subjected to a certain structural adaptation. The key issues here are at least two: identifying the term 'security' as policy objective and defining the policies needed to reach this objective.

\section{Looking for a New Security Paradigm}

Addressing a seminar at the George C. Marshall European Center for Security Studies, Prof. J. Clark emphasized the US efforts to modernize their security system. According to him, 'Homeland Security' embodies 'the preparation for, prevention of, deterrence of, preemption of, defense against and response to threats and aggression directed toward population and infrastructure, as well as crisis management, consequence management and other domestic civil support." He also referred to homeland defense as: "the protection of territory, sovereignty, domestic population and critical infrastructure against direct threats and aggression." It is obviously not easy to initiate policy actions based on these definitions. The US actions in the aftermath of 2001 clearly prove this - highly ambitious at the beginning, focused on the newly established Department of Homeland Security, followed by a continuous search for allocation and balancing responsibilities among institutions, a large-scale project for restructuring intelligence community, huge but dubious defense budget, reassessment of the new social control regime, etc.

The general US approach embodies three more or less separate elements: protection against various terrorist attacks; defense of territorial integrity and sovereignty; assistance in case of disasters, terrorist attacks and other emergencies. This article, 
however, is not intended to make any kind of assessment of the existing US practices. A huge setback for Bulgaria and other similar countries is the current identity dilemma in the field of security. It may sound paradoxical, but the challenges to security policy triggered by transnational terrorism should have been even more serious for us than for the West European countries. Political transition within the last fifteen years was based on the collective approach to foreign policy, security, and defense, voluntary renunciation of part of the national sovereignty, and shared obligation. Along with many other issues, transition meant breaking up with the bastion state, with the notion of 'Fatherland,' whose political survival was more important than the human values, as well as with the notion of 'The War' in which we had to destroy the enemy.

At present, the discussion of the security paradigm in Bulgaria is focused at several levels of analysis: sense of belonging (or not belonging) to the common Euroatlantic values, threat perception (either shared or not), concept for reaction (determination, wait-and-see, and defense), and collective approach (what we can and what we cannot do on our own).

The sense of belonging to a certain civilization cannot be acquired or destroyed in a couple of decades. In the past, within the boundaries of the Ottoman Empire, Bulgaria managed to preserve its values for five centuries. Returning to the roots of their civilization has never been a problem for Czechs and Hungarians, mainly due to the fact they had never really broken with them. Nowadays, Bulgaria's joining the transatlantic system of values in terms of mentality is based on the presumptions of 'no return,' 'this is our world,' and 'we should share the burden (pay the price).' These are more or less political slogans. However, if they could succeed in motivating also the social expectations and individual actions and gain support by gradual achievements in the field of integration, then the idea of belonging will become a key motivating factor and will result in deep 'sharing of values,' while the cultural identity remains intact.

In regard to national security, the threat perception is undergoing continuous changes as a result of such factors and circumstances as the end of the Cold War, the collapse of the Warsaw Pact, the conflict in neighboring Yugoslavia, the emerging Islamic fundamentalism, the transnational terrorism, and the escalating organized crime in the country and in the region. Clearly, terrorism is just one of the driving factors of the nation's current threat perception. Society's expectations and the actions of the politicians are affected not so much by its pure forms of manifestation but by its combination with other factors and circumstances such as Bulgaria's participation in missions abroad-Bosnia, Kosovo, Afghanistan, Iraq - and the presence of large Muslim communities and thousands of Bulgarian Muslims with dual citizenship, relatively loose residence regime of aliens, and last but not least - organized crime engaged in 
'strategic' traffic routes connecting Afghanistan and Turkey with Kosovo, Albania and Colombia, as well as with the West European and the US markets.

It is the nation's historic background that determines the notion about the way security-related issues are tackled, together with the government's determination, the realistic assessment of the country's capabilities, and the maturity level of Alliance mentality.

In Bulgaria, each of these elements is still undergoing thorough transformation. The old Balkan mentality to resolve all issues by means of war is obviously part of the past. However, the flying start of the first nationalist party after the 2005 Parliamentary elections cannot remain unnoticed (Coalition 'Ataka').

The ambitions of the recent Bulgarian governments to escape from the swamp of international isolation (deep enough from the time of Mehmet Ali Agca's assassination attempt of the Pope John Paul II, and the self-imposed isolation during the wars in Yugoslavia in the 1990s) and to demonstrate the qualities of first class-actors in international relations have led to participation in such emblematic events as the NATO operation in Kosovo, the war against terror and driving the Talibans from power in Afghanistan, and the US-led operation in Iraq. Thus, a trend for 'determination' and 'being on the offensive' starts to emerge, which would have hardly happened had the syndromes of demonstrating a sense of belonging, of confirming the breaking up with isolation and of finding proofs for their own value existed.

Another specific issue is to what extent decision makers and society are aware of the real capabilities of the security sector. One of the main difficulties encountered during the pre-mission training for deployment on the Balkans, Afghanistan and Iraq in particular, is that political decisions were made on the presumption that capabilities exist, but only after decisions were made the military started to create the specific capabilities: forming battalions, providing equipment and special training, etc. Considering the different nature of these operations in terms of risk, specific conditions and scale, the issue of existing operational military capabilities for participation in such operations created quite a swell in public interest.

Community spirit in regard to NATO and its member states could not obviously be formed within a year or two, given the difference between NATO and the Warsaw Pact in terms of organizational culture and collective approach. As a result, the spirit of 'collectiveness' is demonstrated mainly on political and professional military level. In order to guarantee political continuity, however, it should be integrated into the nation's system of values.

Apparently, under these circumstances the new security paradigm could no longer be based on the conventional concepts for 'territorial integrity, sovereignty and inde- 
pendence of the country' being the focus of the security policy and main objective of the armed forces and being implemented through a 'defensive military doctrine.' Granted that Bulgaria and other countries from Europe and America, regardless of their potential and ambitions, sincerely desire to join the Euro-Atlantic system of values, they have to accept the paradigm that national security should be guaranteed by effective risk management and prevention of risks escalating into threats as early as possible, preferably in a collective manner. This paradigm thoroughly changes the approach to building national security sectors, sets new requirements in respect to the legislative basis for guaranteeing security within the country, within the alliance and in the world as a whole and creates new regulations concerning the transformation of the armed forces and the other security-related establishments.

\section{The Achilles' Heel: Operationalization of the New Security Paradigm}

The main reason for the slow and strenuous digestion of the new realities in the security sector most probably is a result of the transition's inertia. For much too long states like Bulgaria had focused primarily on themselves - on the political and economic transition within the country and the corresponding 'reforms.' In our case, for instance, democratic control of the security sector, structural demolition of the 'state within the state' and achieving a certain degree of transparency on an organizational level were much more important than efficiency, competence and rationalism under the 'cost-efficiency' criterion. As a result, the security sector organizations turned into institutions 'in waiting': any immediate military effectiveness was not necessary, or at least was not a priority; the interior organizations were subordinated to the primacy of civil rights; the intelligence and counterintelligence were subordinated to competing political goals.

The issue is to what extent inertia has been brought to a close and replaced with the sober understanding that what we are facing now are growing asymmetric threats, ideological and religious extremism and terrorism with globalized long-arms, which makes the effectiveness of the security apparatus paramount and requires different priorities and trade-offs. Events such as the London bombings of July 7, 2005, will no doubt bring politicians and professionals closer to realizing the rationalism of the new security paradigm than, for instance, to giving up the concept that 'security' is equivalent to 'defense.' However, apparently the problem lies in the ability to generate new operational concepts and turning them into systems of well-functioning tools. The so far unsuccessful efforts in regard to the security sector reform concept are an example of this, but we can hardly expect any conclusions to be made out of them. The situation concerning homeland security is quite similar. In the most recent Bulgarian Strategic Defense Review neither of the two concepts was implemented, while modern crisis management systems and human or societal security were not even 
mentioned. These are the facts, although Bulgarians were among the most ardent participants in the debates concerning the thorough transformation of the political, legal and operational aspects of the national security system even before September 11 .

This article is not intended to make a critical analysis of the existing security concepts or offer a new national security system option. Actually, it is offering a number of ideas and approaches in this regard. However, there are several basic points while discussing the various alternatives. Among them are the perceptions for the new political goals of the security system, the vision for national security's global space, the conviction that global threats should be confronted collectively, and that the quest for more security should not extend beyond democratic values.

\section{Guaranteeing absolute security is no longer a plausible political goal}

The architecture and the buildup of the security system used to be based on the presumption that, provided we have perfect organizations engaging the best possible professionals and the state provides sufficient funds, national security is guaranteed. The opposite was quite out of the question both from a political and professional point of view. Therefore, even experts openly declared that either there is or there is no security. Thus, the main issue for the East-European states in the context of their NATO membership was 'To what extent will NATO guarantee our security?', although while analyzing the threat perceptions these same people (mostly politicians and journalists) declared that practically there are no threats for countries like Bulgaria which require NATO protection. Speaking about guaranteed or 100 percent security in our globalized world is pure fantasy. Terrorist attacks in the US and even more the ones in Madrid, Istanbul and London clearly showed that the main issue lies not in 'guaranteeing security,' but in determining the level of insecurity society is ready to accept as normal. The social perception for insecurity is the key decision-making factor as far as security is concerned. The chronically insecure societies are suspicious, irritable and radical in terms of their social and political behavior. Generally speaking, they are prone to making greater cutbacks of civil and democratic freedoms and radical decisions (regulations, budgets, large-scale restructuring, contingency measures) are more easily adopted.

\section{Security can no longer be regarded as internal and external}

Reality leaves far behind the current organizational structure of the national security systems. For countries such as Bulgaria not even one of the existing security risks can possibly emerge and evolve only within the country and none of the current threats can be resolved solely on the country's territory. The presumption for 'external' and 'internal' no longer exists in the sphere of security. In spite of the actual breakthroughs within the police and army sectors, most of the security organizations still follow this course both in terms of concept and structure. Roles and missions, legal 
frameworks and operational concepts are being created for major options with a 5 percent probability, while those which are 95 percent likely to happen are dealt with on an ad hoc basis and from time to time. The Armed Forces consider operations such as the ones in Afghanistan, Kosovo and Iraq as 'non traditional' or 'unconventional.' The system of counter-crime organizations continues to be helpless in regard to internationally-based crime because its notional basis includes the presumption for domestic area of operations and authority. Intelligence and counterintelligence divisions follow the principle of 'external' and 'internal,' although in a world of globalized information technologies, banking, movement of people and commodities this is sheer nonsense.

\section{The capability gap could not be fulfilled on a national basis}

NATO and EU will no longer be security organizations aiming to prevent clashes among the member states by means of integration. The institutional politization as a discussion forum on security issues is being replaced by their operationalization into actual policy instruments. Not even a single issue could be resolved by partial measures on a national level such as quitting the Schengen Agreement in order to strengthen national border control. They only illustrate that, so far, not enough attention has been paid to the international measures for building up capabilities where required and to interactive programming mechanisms. In view of terrorism and other global threats, the efficiency of the security instruments becomes crucial. Interoperability should be related not only to NATO member states and military establishments. Interoperability is the basis for combined and joint operations of military and interior forces but also for all inter-agency - both national and international-actions. Netcentric operations should also be further developed and implemented as doctrine both internationally and within the national institutions. Advanced multinational research and development and integration of defense industries into a perspective source of coalition security advantage are important components of this approach.

\section{The virtues of democracy should be used as foundations for building up the new} security system

Democracy must not be used as an excuse for the lack of efficiency of the security system in our world and this is more than obvious. Democracy's biggest strength lies in the people's concern for the future of the nation and the state, i.e. the lack of principal antagonism between citizen and political authority. This means that key issue of the required new security policy is the authorities' manner of addressing and getting people involved in security measures. This means that attacks on the Euroatlantic democratic system require, more than ever, democracy. Professor Dominique Moissi said in Sofia: "The first answer for us is to be even more democratic than we are. This is what the enemy wants us to become: to close our system, to violate these democratic principles of which we are so proud. The answer to violence is democracy." $\mathrm{He}$ 
came up with a very important conclusion regarding the 2003 Madrid bombing: the reason for turning the vote in the parliamentary elections in Spain is mainly the failure of the then-government to openly and frankly tell Spanish people: "Well, it may be Al Queda's doing, but it is not because of the war in Iraq. It is because we are liberal democracy and we are to fight it together."

Perfect civil control, transparency in planning and functioning of the security sector organizations, efficiency and competence of parliamentary oversight must be promptly and cleverly modernized in order to meet the challenges posed by transnational terrorism. Being a pillar of civil society and democracy, they could not possibly be questioned or restricted without discussion. The time of closed-type organizations is definitely over. We must keep in mind, however, that even perfect civil control and transparency could easily turn them into ineffective or simple political instrument (especially in the underdeveloped democracies of Eastern Europe). Control and transparency must have a mission and objective. Control and transparency without objective and purpose might make things even worse.

\section{New organizational culture is a must}

Practically all efforts so far to conceptualize national security sectors have more or less failed. It is obvious that archaic standards prevail for reserved perimeters, unique obligations, vertical organizations and relationships, etc., whose origin lies in the selfgenerated presumption that security organizations (and their personnel) are the true patriots and the only saviors of the nation in case of calamity.

No doubt things have changes in the aftermath of the Cold War. Some doubts remain in regard to the ways security sector could be organized and could perform. Analysts from the East have often observed with some envy the existing practices in the USA and other countries to create horizontally organized and manageable structures, declaring that the only way to avoid the destructive effect of hierarchically structured organizational behavior is by creating a real security community. Today, we are witnessing an increasing centralization in the West, intelligence and security services included. This is a serious cultural issue which could be overcome only after thorough social and psychological analyses and decision modeling for defining the true balance between organizational tradition and mentality and modern management procedures.

\section{Legal bases of security must form the nation's future}

Many of the reforms in East Europe, both past and present, are or were focused on eradicating atrocious or ineffective legacy from the past. Regulations and mechanisms for their implementation in most of the cases addressed problems, which had already occurred in certain countries, and were intended to prevent their happening again. These regulations were very short-lived. The current Defense and Armed Forces Law in Bulgaria was adopted in 1995 as a reflection of the most serious clash between the 
Minister of Defense and the Chief of the General Staff (the most senior military official in the country). The Law's ideology lies in the presumption to 'define and differentiate' the military and civil sectors and limit any possible mutual intervening. Ten years after its adoption, this law still generates a mentality of differentiation which is spreading not only among military and civilian personnel but within the whole society.

In order to function properly, the new security paradigm must be backed up by innovative laws and regulations, shaping the ethos of the experts engaged in the security sector as well as the nation's character as far as broad security sector issues are concerned. They should focus not on past problems but on future demands. The effect of the new legislation, for instance, will become visible after one generation of officers (accounting for the example of Innere Führung in Germany).

\section{Remodeling of the security system must boost the democratic political system}

The real situation, especially in the East European countries, is that while the democratic political system was practically newly established, the national security systems were subjected to reforms or restructuring. Thus, the new Bulgarian Constitution adopted in 1991 created four power centers - Parliament, President (directly elected by the people), Government (endorsed by Parliament), and independent judicial system (including Constitutional Court ensuring the supremacy of the Constitution). This pattern, along with the distribution of prerogatives, displays the existing at that time concerns about the return of authoritarianism rather than any ambition for creating a simplified and efficient political management system. The distribution of security organizations among the power centers is motivated by the system of checks and balances. Thus, the President has direct control over the National Intelligence Service and the National Guard Service and is Supreme Commander of the Armed Forces although he has no rights to initiate any regulatory acts or to exert influence on their budgeting. Obviously, in a situation like this, the system's efficiency starts to depend on the leaders and how well they work together rather than on hierarchy and formal relationships. In a number of similar cases, one of the possible means for countering terrorism and other unexpected threats is creating a government-affiliated Security Council, incorporating the existing information and analyses, and a corresponding position of National Security Counselor or National Director of Intelligence. These are the so called 'expedient' solutions. Actually, in some cases like the one in Bulgaria, it is a matter of forming up a new center of influence, which might considerably transform the relationships within the system of checks and balances.

Another aspect of this principle is the setting up of a national system for crisis response or for civil protection. So far the approach has been in favor of a centralized model of ministerial type. The resulting effect is that in case of a calamity local peo- 
ple regard themselves as doomed while those coming from the so called 'center' look like saviors to them. This definitely does not help direct democracy and undermines the idea for a strong local government.

\section{Conclusions}

The nature of global security has changed over the past twenty years or so. Practically, it seems that two dates and one single process are dominating over our present. The dates are November 9, 1989 when the Berlin Wall collapsed, and September 11, 2001 when terrorists wiped out one of the symbols of the free world. The process is globalization - political, economic, cultural, informational and in the field of security. No doubt terrorism is one of the dark sides of globalization coming up to show that besides the free flow of finances and commodities, unfortunately there is a possibility for merging and intermingling of threats and risks. We are now witnesses of a new phenomenon - never before in mankind's history such a small group of people has had the opportunity to threaten so many people. It is just the opposite to the famous quote of Churchill: "Never did so few people do so much for so many."

The present situation could be described in a number of ways, but I believe it is mainly caused by the technological gap and the lack of progress in human ethics. This is a problem we all must face with the awareness that we are living in a totally dependant and globally united world: we have no place to hide or to retreat from the existing problems. It is totally unacceptable to be divided no matter what the reason might be. Like never before we are all in one boat. This is why the quest for a new security paradigm and the subsequent operational models and decisions is like never before a matter of collective effort. One of our biggest challenges is the need of thorough and multivariate analyses as well as prompt actions leading to concrete results. In fact, no one has any time for making experiments and errors. The joint efforts for this edition of Information and Security are modest although much needed contribution in the quest for finding constructive solutions. It does not matter whether they will be found within the context of homeland security, crisis management, human or societal security or another conceptual framework. What really matters is the effectiveness of the policy and its implementation so that terrorists are never allowed to set the security agenda. 
VALERI RATCHEV is Colonel of the Bulgarian Armed Forces. He is Deputy Commandant of "G.S. Rakovski" Defense and Staff College and Dean of its National Security and Defense Faculty. In this position he is responsible for senior military officers' education and civilmilitary training on security and defense policy and management. Col. Ratchev has considerable experience in conceptualization and documentation on national security, crisis management, defense doctrine and force reorganization. He has published extensively on international security issues, defense reform and civil-military relations. E-mail: ratchevv@yahoo.com. 